\title{
REPRESSÃO E INCONSCIENTE NO DESENVOLVIMENTO DA METAPSICOLOGIA FREUDIANA
}

Fátima Caropreso e Richard Theisen Simanke

Fátima Caropreso
Professora adjunta
do Departamento
de Psicologia da
Universidade
de Juiz de Fora
(UFJF), docente
e orientadora
do Programa de
Pós-Graduação em
Psicologia da UFJF.
Richard Theisen Simanke
Professor associado
da Universidade
Federal de
Juiz de Fora
(UFJF), docente
e orientador
de mestrado e
doutorado do PPG
em Psicologia da
UFJF e do PPG
em Psicologia da
Ufscar, pesquisador
do CNPq (Nível
1-D).

Fátima Caropreso Professora adjunt artament Universidade de Juiz de Fora e orientadora do Programa de Pós-Graduação em

Richard Theisen Simanke Professor associado Federal de (UFJF), docente
RESUMO: Procura-se acompanhar o desenvolvimento do conceito de repressão na teoria freudiana e discutir a relação entre as noções de repressão e de inconsciente nos diversos momentos da obra de Freud. Procura-se também desfazer alguns equívocos frequentes de interpretação - como a ideia de que, inicialmente, para Freud, o inconsciente coincidiria com o reprimido - e enfatizar algumas reformulações importantes que costumam passar despercebidas aos comentadores de Freud, como a vinculação do reprimido primordial a traumas reais, em 1926, que teve por consequência uma relativização do papel da sexualidade e da castração na etiologia das neuroses e na dinâmica psíquica como um todo.

Palavras-chave: Inconsciente, repressão, repressão primordial, trauma, angústia.

ABSTRACT: Repression and unconscious in the development of Freudian`s meta-psychology. This paper follows the development of the concept of repression in Freud's theory and discusses the relationship between the notions of repression and unconscious in different moments of his work. It seeks to undo some frequent interpretative mistakes, such as the idea that Freud initially conceived the unconscious as identical to the repressed. It also emphasizes some important revisions which go often unnoticed to Freudian scholars, for example, the linking of primordial repression and real traumas in 1926, which brought as a consequence a relativization of the role played by sexuality and castration both in neuroses' etiology and in the psychical dynamics as a whole.

Keywords: Unconscious, repression, primordial repression, trauma, anxiety. 
D retendemos aqui analisar o desenvolvimento do conceito de repressão na 1 teoria freudiana desde o Projeto de uma psicologia, passando por seus principais textos metapsicológicos, até Inibições, sintoma e angústia. O foco inicial do trabalho será o histórico das relações entre as noções de repressão e de inconsciente no âmbito da metapsicologia, a fim de analisar de que maneira essa relação e esses conceitos são pensados nas diversas etapas do seu desenvolvimento. Essa análise permitirá também desfazer alguns equívocos relativamente frequentes na interpretação dessas questões, como, por exemplo, a ideia de que, para Freud, num período inicial, o inconsciente coincidiria com o reprimido. Procuramos, ainda, ao final, chamar a atenção para alguns fatos que parecem ter recebido pouca atenção por parte dos intérpretes da obra freudiana, como é o caso da vinculação do reprimido primordial a traumas precoces reais, a partir de 1926, o que teria por consequência uma relativização do papel da sexualidade e da castração na etiologia das neuroses e, num sentido mais amplo, na explicação da dinâmica psíquica como um todo.

\section{INCONSCIENTE E REPRESSÃO NO PROJETO DE UMA PSICOLOGIA}

No Projeto de uma psicologia, como se sabe, Freud formula a hipótese de um aparelho neuronal, que seria constituído por três sistemas de neurônios: o sistema de percepção (phi), o sistema de memória (psi) e o sistema responsável pelo surgimento das qualidades sensoriais e da consciência (ômega). O campo da consciência seria restrito em relação ao da memória, e apenas parte das representações — ou seja, dos processos que ocorressem em psi - tornar-se-ia consciente. Assim, a representação é concebida como um fato de memória independente da consciência; esta última, por sua vez, define-se como algo que pode ou não se acrescentar a uma parte das representações, desde que cumpridas certas condições, como a vinculação com a percepção ou com a linguagem. Antes da constituição das associações linguísticas, não haveria possibilidade de rememoração consciente. Portanto, até então, a consciência dependeria diretamente das propriedades da percepção. A constituição das representações de palavra traria consigo a possibilidade de outra forma de consciência, intermediada pelos signos linguísticos. Como parte das representações de objeto, presumivelmente, não chegaria jamais a ser associada a representações de palavra - poderia haver representações que permanecessem sempre "insuscetíveis de consciência". (SIMANKE \& CAROPRESO, 2005)

Assim, a distinção entre as representações suscetíveis e aquelas insuscetíveis de consciência se limitaria ao fato de as primeiras serem representações de objeto associadas a palavras e de as últimas serem representações de objeto sem essa associação. Tanto uma quanto a outra seriam, no funcionamento psíquico 
normal, governadas pelo processo secundário: elas não possuiriam propriedades diferenciais e apenas a presença ou ausência do vínculo com palavras as distinguiria. No Projeto, portanto, já encontramos a hipótese de um inconsciente dinâmico, da existência de processos inconscientes e psiquicamente ativos, mas não há ainda a hipótese do inconsciente como um sistema específico, a qual só irá aparecer na Carta 52 e desenvolver-se em $A$ interpretação dos sonhos. (CAROPRESO, 2008; 2010)

Na segunda parte do Projeto, Freud procura explicar como se dá a formação dos sintomas da histeria a partir da falha dos mecanismos de defesa do eu. No caso da defesa normal, uma representação associada a uma vivência de dor seria evitada no curso dos processos de pensamento, embora pudesse tornar-se consciente se evocada por estímulos externos. Ao contrário, na repressão histérica, a recordação patogênica seria totalmente excluída da consciência. Em seu lugar, apareceria outra representação a ela associada, acompanhada pela liberação de afeto. Nesse caso, essa liberação seria incitada por essa representação substitutiva, que Freud define como um símbolo da que se encontra reprimida; por isso, a sua inibição não seria possível. Tratar-se-ia de um processo primário póstumo, isto é, que ocorre após a formação do eu e escapa a sua ação inibidora.

Freud argumenta que essa falha do mecanismo normal de defesa se deveria ao fato de que as representações patogênicas inconscientes não teriam sido traumáticas na origem - não teriam, originariamente, feito parte de uma vivência de dor, adquirindo seu caráter traumático apenas em um momento posterior, após a emergência da sexualidade. Como se sabe, no momento da redação do Projeto, Freud trabalhava com a hipótese de que experiências reais de abuso sexual estariam na origem da histeria, além de manter a hipótese de que a sexualidade só surgia na puberdade. Assim, apenas após a puberdade, essas experiências poderiam ser compreendidas como sexuais, e só então adquiririam um caráter efetivamente traumático. Quando a recordação da cena de sedução fosse, de alguma maneira, reativada, ela produziria uma excitação sexual que seria convertida em angústia. O mecanismo de defesa entraria em ação para proteger o aparelho dessa angústia; no entanto, seu êxito seria parcial, pois, embora a recordação traumática fosse reprimida e se tornasse inconsciente, o afeto continuaria sendo evocado em associação à outra representação, aparentemente inócua. Essa defesa imperfeita levaria à produção do sintoma.

Então, até esse momento, a histeria é explicada como efeito de um trauma real vivido na infância. Experiências traumáticas relacionadas à sexualidade estariam na origem da repressão e da neurose, embora seus efeitos só viessem a se manifestar posteriormente. Quando Freud, mais tarde, conclui que as representações reprimidas não são produtos de vivências reais, mas de fantasias sexuais infantis - o que impunha a conclusão de que a sexualidade já se manifestaria 
na infância e que a repressão atuaria sobre desejos, não sobre recordações objetivas - , ele se vê obrigado a explicar como um desejo pode vir a ser reprimido. A estratificação do sistema de memória, proposta na Carta 52, fornece um caminho para a solução desse problema.

\section{INCONSCIENTE E REPRESSÃO NA CARTA 52}

Na Carta 52 (FREUD, 1892-99/1998), Freud formula a hipótese de que a formação do psiquismo é um processo de estratificação sucessiva, e de que os traços mnêmicos estão sujeitos a reordenações de tempos em tempos, com o estabelecimento de novos nexos entre eles. Essas retranscrições dariam origem a diferenciações internas ao sistema de memória, que representariam modos de operação psíquica característicos de épocas sucessivas da vida. Freud argumenta que haveria no mínimo três tipos de transcrições, que designa por "Ps" (signos de percepção), “Icc" (inconsciência) e "Prcc" (pré-consciência). Estes corresponderiam a sistemas que se ordenariam entre o órgão responsável pela percepção (P) e a via para a descarga motora (M). Em cada um deles, as representações estariam organizadas de acordo com princípios associativos diversos.

No sistema psi do Projeto, toda facilitação seria determinada pela ocupação simultânea de neurônios adjacentes e, portanto, a constituição das representações e suas associações se dariam de acordo com relações de simultaneidade. Na Carta 52, Freud sustenta que há também associações que ocorrem conforme outros tipos de relações, como a causalidade, por exemplo — sugerida, nesse momento, como o princípio organizador do inconsciente. A simultaneidade corresponderia apenas ao sistema dos signos de percepção. O nível mais evoluído de organização — o Prcc — seria aquele em que surgiriam as associações linguísticas. Nesse nível, o pensamento poderia se tornar consciente, mediante a "ativação alucinatória" dos traços de percepção da linguagem.

Esse processo de transcrição dos traços mnêmicos poderia não ocorrer a uma parte do material representacional, caso isso resultasse em desprazer. Isso é o que, nesse momento, Freud define como repressão. As representações reprimidas seriam, então, aquelas que não foram traduzidas devido ao desprazer que se produziria. Em consequência, essas representações nunca chegariam a ter acesso às representações de palavra, permanecendo insuscetíveis de se tornarem conscientes pela via normal do pensamento. A repressão, segundo Freud, seria uma defesa patológica; a defesa normal seria aquela que ocorresse dentro de um mesmo sistema de transcrições, a partir da inibição do eventual desprazer gerado pela ativação da representação.

Como vimos acima, no Projeto, a existência de um psiquismo inconsciente é afirmada com clareza, com a formação das representações enquanto tais sendo 
conceitualmente distinguida da sua relação com a consciência. Mas ali, o inconsciente ainda designa apenas um estado da representação, e não o pertencimento a um grupo psíquico dotado de características próprias: pode-se dizer de uma representação que ela "é” ou "está” inconsciente, mas não que ela "está no" inconsciente. É apenas na Carta 52 que Freud começa a elaborar uma noção de inconsciente no sentido sistemático — isto é, como um sistema de representações diferenciado, regido por um princípio associativo específico — , uma ideia que será desenvolvida em $A$ interpretação dos sonhos. No entanto, não é possível, nesse momento, identificar o sistema inconsciente com o psiquismo inconsciente como um todo, nem com o psiquismo insuscetível de consciência: suas representações constituiriam apenas uma parte deste último, uma vez que as representações do sistema dos signos de percepção tampouco poderiam se tornar conscientes pela via normal do pensamento. A capacidade para tanto estaria presente apenas nas representações do sistema pré-consciente. Então, com o desdobramento do sistema de memória proposto por Freud, a diferenciação, já presente no Projeto, entre o inconsciente suscetível e aquele insuscetível de consciência recebe uma representação tópica. O Icc e os sistemas que o precedem representariam este último, e o Prcc representaria o primeiro.

Seria possível afirmar que, na Carta 52, o inconsciente coincide com o reprimido? As representações que permanecessem integrando o sistema inconsciente seriam aquelas que não foram transcritas de acordo com suas relações verbais. Como, nesse momento, Freud chama de repressão a esse processo de falta de tradução, é possível dizer que sim: todas as representações que integram o sistema inconsciente encontram-se reprimidas. Não apenas elas, porém, mas também aquelas que integram o sistema dos signos de percepção. Portanto, o inconsciente, em sentido estrito, seria apenas uma parte do reprimido. No entanto, em 1900, Freud passa a conceber a repressão de outra forma e não mais será possível sustentar que o inconsciente coincida com o reprimido.

\section{INCONSCIENTE E REPRESSÃO EM $A$ INTERPRETAÇÃO DOS SONHOS}

Na seção B do Capítulo 7, Freud retoma a ideia de que existem múltiplos sistemas de memória. Na Carta 52, ele afirmara não saber quantos sistemas deveria haver (no mínimo três, conjeturara, provavelmente mais). No esquema apresentado em 1900, outros sistemas de memória são inseridos entre o sistema de percepção e o do inconsciente. Freud esclarece aí que a representação tópica dos sistemas é uma construção auxiliar utilizada com fins, em princípio, didáticos e que esses sistemas deveriam corresponder, de fato, a processos diferentes. Assim, no início da seção F, ele afirma: 
“Se as consideramos com maior atenção, as elucidações psicológicas da seção anterior não nos sugerem a suposição da existência de dois sistemas perto do extremo motor do aparelho, mas sim de dois processos ou de dois modos no decurso da excitação. Para nós dá na mesma; sempre devemos estar dispostos a abandonar nossas representações auxiliares quando nos acreditamos em condições de substituí-las por alguma outra coisa que se aproxime mais da realidade desconhecida." (FREUD, 1900/1982, p.578)

Os dois últimos sistemas mnêmicos seriam o Inconsciente (Icc) e o Préconsciente (Prcc). Este último estaria ligado à consciência e governaria o acesso à motilidade voluntária. O inconsciente corresponderia ao processo primário, caracterizado pelo livre fluxo de quantidade, e o pré-consciente corresponderia ao processo secundário, caracterizado pela retenção de uma parte da excitação nas representações. Portanto, a diferença entre dois "modos no decurso da excitação" seria aquela entre o estado "livre" e o estado "ligado" ou "quiescente" da quantidade - uma distinção que data dos Estudos sobre a histeria e do Projeto. Apesar de ser uma representação menos rigorosa, a tópica deve continuar sendo utilizada, diz Freud, uma vez que ela figura de maneira mais compreensível a diferenciação em questão.

Portanto, a representação dos sistemas como dois lugares espacialmente distintos é apenas uma das maneiras de representar a diferença entre o psíquico suscetível e o insuscetível de consciência, mas não a única e nem sequer a melhor. Para representar as características dos sistemas Prcc e Icc, pode-se usar um modelo topográfico ou, mais rigorosamente, pensar em dois tipos de processos: essa última alternativa seria aquela que mais se aproximaria da "realidade desconhecida” do psiquismo.

O processo primário estaria presente desde o início - ele representaria a tendência primordial do aparelho para descarregar toda a excitação — , ao passo que o processo secundário seria pouco a pouco estabelecido a partir da inibição do primário. Essa inibição, no entanto, não atingiria a totalidade dos processos: uma parte dos mesmos ficaria permanentemente subtraída à influência do Prcc, devido, sobretudo, ao estabelecimento tardio do processo secundário. As representações não inibidas continuariam submetidas ao processo primário e permaneceriam, assim, insuscetíveis de se tornarem conscientes pela via normal do pensamento, pela intermediação do Prcc e das associações propiciadas pela linguagem. Outras representações se encontrariam também nesse mesmo estado, a saber, aquelas que foram reprimidas. Estas teriam sido um dia pré-conscientes; no entanto, por se tornarem representações substitutivas daquelas inaceitáveis para os processos secundários, teriam sido excluídas do Prcc, voltando a ser governadas pelo processo primário. 
As representações originariamente inconscientes seriam pré-condição para a existência das reprimidas. Para explicar a repressão, Freud começa afirmando que um conjunto de "moções de desejos" infantis permaneceria inapreensível e não passível de inibição pelo processo secundário. Devido ao estabelecimento tardio desses processos, tais moções não chegariam a ser incorporadas ao Prcc, e o processo secundário não seria capaz de inibir o desprazer eventualmente causado por elas. Essas moções de desejo se dividiriam em dois grupos: aquelas cuja realização não seria desprazerosa para o Prcc e aquelas cuja realização produziria um desprazer impossível de inibir. As primeiras, embora não passíveis de inibição e inapreensíveis para os processos secundários, seriam direcionadas por estes pelo caminho mais adequado:

“Em consequência deste surgimento tardio do processo secundário, o núcleo do nosso ser, que consiste em moções de desejos inconscientes, permanece inapreensível e não passível de inibição para o pré-consciente, cujo papel ficou limitado, de uma vez por todas, a indicar às moções de desejo provenientes do inconsciente os caminhos mais adequados ao seu fim." (FREUD, 1900/1982, p.572)

Aquelas moções de desejo cuja realização se tornasse desprazerosa permaneceriam totalmente fora da influência do Prcc:

“(...) entre estas moções de desejo indestrutíveis e não passíveis de inibição (...) se encontram também aquelas cuja realização entrou em relação de contradição com as representações-meta do processo secundário. A realização desses desejos já não provocaria um afeto prazeroso, e sim desprazer e justamente esta mudança do afeto constitui a essência do que designamos 'repressão'." (FREUD, 1900/1982, p.573, grifos nossos)

Essas moções de desejo manteriam sempre a aspiração de alcançar a consciência, o acesso à motilidade, e atingir sua satisfação. Embora as representações originariamente associadas ao desejo inconsciente nunca chegassem a se submeter ao processo secundário, a excitação a elas associada buscaria sempre ingressar no Prcc. Por isso, este sistema teria que fazer um esforço contínuo no sentido oposto para proteger-se contra a irrupção da excitação oriunda do inconsciente - o que mais tarde, Freud vai chamar de contraocupação (Gegenbesetzung). Em alguns casos, no entanto, esse mecanismo falharia; assim, a excitação de desejo conseguiria ingressar no processo secundário e ocupar uma representação pré-consciente, o que teria como consequência a produção de desprazer. Nesse caso, a tendência geral do aparelho para evitar o desprazer faria com que a ocupação pré-consciente dessa representação fosse retirada, e a mesma cairia sob o domínio do processo 
primário, tornando-se inconsciente e insuscetível de consciência. Esse processo de retirada da ocupação de uma representação pré-consciente é agora definido como repressão.

A ocupação de uma representação pelo Prcc só ocorreria quando nenhum desprazer intolerável resultasse dessa ocupação ou quando este pudesse ser inibido: “o segundo sistema só pode ocupar uma representação se está em condições de inibir a liberação de desprazer que parte dela” (FREUD, 1900/1982, p.571). Essa retirada da ocupação da representação seria, então, uma consequência direta da tendência do aparelho a evitar o desprazer e da regulação de seu funcionamento pelo princípio de desprazer - que Freud, mais tarde, passará a chamar de princípio de prazer. Sendo assim, dois tipos de representações permaneceriam sob o domínio do processo primário e insuscetíveis de consciência pela via normal do pensamento: as reprimidas e as vinculadas às moções de desejo que nunca foram integradas ao Prcc. Estas últimas, ao contrário das primeiras, nunca teriam sido incorporadas ao processo secundário, tendo permanecido inconscientes desde sua origem. Em $A$ repressão, Freud formula a hipótese de que essas representações seriam alvo da repressão primordial, enquanto as primeiras sofreriam a repressão propriamente dita. No Capítulo 7, essa noção de repressão primordial ainda não aparece e, portanto, não é possível afirmar que o sistema inconsciente coincide com o reprimido, uma vez que apenas aquelas representações desocupadas pelo processo secundário podem ser chamadas de reprimidas.

Em síntese, de acordo com a Carta 52, a repressão consistiria na falta de tradução de uma representação conforme os princípios associativos do sistema seguinte ao que ela se encontra. No Capítulo 7, Freud a concebe como a retirada da ocupação pré-consciente de uma representação, com a consequente exclusão desse sistema e do processo secundário. A repressão, portanto, não é mais pensada como qualquer ausência de transcrição, em qualquer etapa da constituição do aparelho, mas como um processo mais específico, que se dá entre os sistemas pré-consciente e inconsciente. Dessa forma, no Capítulo 7, o reprimido constitui apenas parte do sistema inconsciente: aquela que alguma vez havia sido incorporada ao processo secundário, mas que fora, pelas razões que se viu, excluída deste último.

\section{INCONSCIENTE E REPRESSÃO: DO CASO SCHREBER AOS ARTIGOS METAPSICOLÓGICOS}

Em O inconsciente, Freud se pergunta se a passagem do sistema Icc ao Prcc acontece mediante novas transcrições das representações — suposição tópica — ou por conta de uma mudança de estado, com o surgimento de um modo de ocupação distinto 
para as mesmas representações — suposição funcional. Essa questão é respondida apenas na última seção do texto, na qual ele chega à seguinte conclusão:

"O sistema Icc contém as ocupações de coisa dos objetos, que são as ocupações de objeto primárias e genuínas. O sistema Prcc nasce quando essa representação de coisa é sobreocupada, devido à ligação com as representações de palavra que lhe correspondem. Podemos conjeturar que essas sobreocupações sejam as que produzem uma organização psíquica mais elevada e possibilitam a substituição do processo primário pelo secundário, que governa no interior do Prcc. (...) A representação não apreendida em palavras — ou o ato psíquico não sobreocupado — fica então para trás, no interior do Icc, como algo reprimido.” (FREUD, 1915a/1982, p.160)

Freud retoma, assim, os conceitos de representação de palavra e representação de objeto, formulados, pela primeira vez, em 1891, para tentar dar conta da diferença entre as representações pré-conscientes/conscientes e as inconscientes. O que ele chama, agora, de representação de coisa corresponde ao que se denominava representação de objeto em 1891. Em O inconsciente, a representação de objeto passa a designar o complexo formado pela representação de palavra mais a representação de coisa.

Desse modo, enquanto houvesse apenas representações de coisa no aparelho, só poderia haver processos primários. Mais tarde, as representações de palavra surgiriam e se associariam a parte das representações de coisa, ocasionando a sua sobreocupação. Como resultado, surgiria no aparelho um nível de funcionamento dotado de uma forma de organização mais elevada, que Freud denomina Prcc. Esse nível de organização corresponderia ao processo secundário e, portanto, a diferenciação entre o Icc e o Prcc continua sendo identificada com a que ocorre entre o processo primário e o secundário. O sistema Icc corresponderia ao processo primário, que incluiria apenas representações de coisa, e o sistema Prcc corresponderia ao processo secundário, que incluiria representações de coisa associadas a representações de palavra. A principal novidade em comparação ao Capítulo 7 é que Freud especifica, em 1915, que é a palavra que possibilita a ligação da excitação em estado livre e que o surgimento do processo secundário é uma consequência da sobreocupação trazida pela representação de palavra.

Na terceira parte do Caso Schreber, há uma descrição da repressão muito próxima daquela presente em $A$ repressão. Ali, Freud distingue três etapas do processo. $\mathrm{Na}$ primeira, ocorreria uma "fixação": a inibição no desenvolvimento de uma pulsão e a consequente permanência da mesma num estado mais arcaico. Nesse caso, diz Freud, “a corrente libidinal respectiva se comporta a respeito das formações psíquicas posteriores como uma que pertença ao sistema do inconsciente, como uma reprimida” (FREUD, 1911/1998, p.62). Essa primeira etapa seria pré-condição para a ocorrência da "repressão propriamente dita", que corresponderia à 
segunda etapa do processo: ela partiria dos sistemas suscetíveis de consciência e se voltaria contra os derivados psíquicos daquelas pulsões anteriormente fixadas. Quando estas últimas, por se terem fortalecido de alguma maneira, conseguissem se infiltrar nos sistemas conscientes, haveria conflito entre elas e as pulsões de acordo com o eu, o que levaria à repressão. Freud discrimina ainda uma terceira fase: o "retorno do reprimido" devido a um fracasso parcial da repressão, que teria como consequência uma regressão do desenvolvimento libidinal.

Em $A$ repressão, Freud retoma essa descrição e acrescenta a ela a hipótese de que a primeira etapa consistiria na repressão primordial. A fixação da pulsão, mencionada em 1911, seria, então, o resultado desta última. Diz ele:

“(...) temos razões para supor uma repressão primordial, uma primeira fase da repressão que consiste em que, ao representante psíquico da pulsão (...), se negue a admissão na consciência. Assim, se estabelece uma fixação; a partir desse momento, o representante em questão persiste imutável e a pulsão continua ligada a ele." (FREUD, 1915b/1982, p.109)

Assim, a partir dos artigos metapsicológicos, Freud passa a diferenciar entre uma "repressão primordial" — que consistiria na recusa do representante de pulsão por parte do pré-consciente (ou do processo secundário), o que teria como consequência a fixação desta no Icc — e a "repressão propriamente dita" - que seria a retirada da ocupação pré-consciente de uma representação, à qual o representante de pulsão se tivesse associado. Como ele já havia dito no Capítulo 7, duas forças cooperariam para a repressão propriamente dita: a repulsão por parte do pré-consciente e a atração exercida pelos desejos inconscientes. A ocupação retirada seria aquela da representação de palavra. Como vimos, quando a representação de coisa fosse sobreocupada pela palavra, passaria a fazer parte do nível de organização superior, isto é, do Prcc; quando essa sobreocupação fosse retirada, a representação de coisa deixaria de fazer parte do Prcc e voltaria a ser incorporada ao Icc, isto é, a comportar-se segundo os termos do processo primário. A representação reprimida seria, portanto, ou a representação de coisa que perdeu o seu vínculo com a palavra (no caso da repressão propriamente dita) ou aquela que nunca estabeleceu esse vínculo (no caso da repressão primordial). Apenas em 1915, Freud expõe claramente essa ideia que já estava implícita desde o Projeto. No artigo metapsicológico sobre o inconsciente, ele afirma:

“Agora podemos formular de maneira precisa isso que a repressão, nas neuroses de transferência, recusa à representação rechaçada: a tradução em palavras (...). A representação não apreendida em palavras, ou o ato psíquico não sobreocupado, fica para trás, no interior do Icc, como algo reprimido.” (FREUD, 1915b/1982, p.160) 
Sendo assim, o reprimido primordial consistiria naquelas representações de coisa que nunca foram sobreocupadas pelas representações de palavra, enquanto o reprimido propriamente dito seria formado pelas representações de coisa que perderam seu vínculo com as palavras, por terem sido associadas ao reprimido primordial e se tornado, assim, fonte de desprazer para o Prcc. Com isso, somente nesse momento e num sentido bastante específico, parece ser possível sustentar que o sistema Icc seja constituído pelo reprimido e coincida com o mesmo, desde que se entenda por isso o conjunto formado pelo reprimido primordial e pelo reprimido propriamente dito. No Capítulo 7, Freud já afirmara que o núcleo do Icc era constituído por moções de desejo que nunca se tornaram pré-conscientes, mas não havia ainda ali o conceito de repressão primordial; só as representações excluídas do Prcc eram então consideradas como tendo sido reprimidas e, portanto, o reprimido só poderia abranger uma parte do sistema inconsciente.

Além disso, Freud introduz, em 1915, a hipótese de que as representações alvo da repressão primordial seriam os "representantes de pulsão" (no Capítulo 7, ele se referia às mesmas como “moções de desejo”). No entanto, a própria natureza desses representantes de pulsão permanece pouco clara, de modo que é difícil estabelecer plenamente o sentido do reprimido primordial. Apenas em 1926, encontramos elementos para esclarecer essa questão. Ali, Freud vincula a repressão primordial a vivências traumáticas originárias, o que contribui para lançar uma nova luz a respeito do conceito de repressão primordial e do tipo de processos sobre os quais esta incide.

\section{A REPRESSÃO EM INIBIÇÕES, SINTOMAS E ANGÚSTIA}

Na segunda parte de Inibições, sintomas e angústia, Freud apresenta uma hipótese que contribui para a solução de um problema que havia permanecido em aberto, sobre os motivos da repressão primordial: “É inteiramente verossímil que fatores quantitativos, como a intensidade hipertrófica da excitação e a ruptura da proteção antiestímulo constituam as ocasiões imediatas das repressões primordiais" (FREUD, 1926/1998, p.90, grifos nossos).

No Projeto de uma psicologia, Freud havia definido essa ruptura da barreira antiestímulo como constituindo a vivência de dor. Em Além do princípio do prazer (1920/1982), Freud passa a chamar de trauma esse mesmo processo. Em 1926, essa noção é retomada para explicar a repressão que estaria na gênese das neuroses.

Em continuidade, Freud estabelece que a característica em comum de todos os afetos de angústia é representar uma "reação diante de um perigo" e que, nas neuroses, seria a angústia que levaria à repressão. Ele propõe, então, a hipótese de que o protótipo de todas as experiências de angústia seria o trauma do nascimento: 
“(...) o estado de angústia é a reprodução de uma vivência que reuniu as condições para um aumento do estímulo (...). No caso dos seres humanos, o nascimento nos oferece uma vivência arquetípica de tal índole, e por isso nos inclinamos a ver no estado de angústia uma reprodução do trauma do nascimento.” (FREUD, 1926/1998, p.126)

No nascimento, o perigo em questão careceria ainda de qualquer conteúdo psíquico. O recém-nascido só seria capaz de perceber a perturbação na economia de sua libido narcisista, e o afeto de angústia ressurgiria nele em todas as situações que, de alguma maneira, lhe recordassem o nascimento. Mas qual elemento, nessas outras experiências, traria de volta essa recordação e reproduziria angústia? - pergunta-se Freud. Ao analisar as ocasiões que causam angústia na infância, ele conclui que uma condição sempre está presente: a ausência de um objeto bastante estimado, que representa para a criança o risco de se ver novamente diante de um aumento de estimulação frente ao qual ela ficaria impotente, tal como ocorrera na ocasião da "angústia primordial” do nascimento. Assim, Freud crê encontrar aí uma resposta para a questão formulada:

\footnotetext{
“(...) a situação da insatisfação em que as magnitudes de estímulo alcançam um nível desprazeroso (...), tem que estabelecer, para o lactente, a analogia com a vivência do nascimento, a repetição da situação de perigo; (...) este fator constitui, pois, o núcleo genuíno do "perigo" (...). A criança não precisa guardar do seu nascimento nada mais do que essa caracterização do perigo.” (FREUD, 1926/1998, p.130)
}

Freud conclui que a angústia é, em última análise, a expressão do desamparo psíquico do lactente, o qual, por sua vez, deriva de seu desamparo biológico, ou seja, da prematuração do ser humano ao nascer. Ele estabelece, então, uma relação entre as experiências de angústia ao longo do desenvolvimento infantil e o trauma originário do nascimento. O nascimento seria a experiência primordial de angústia, quando o perigo em questão fora o aumento brusco e intenso da estimulação, frente ao qual o recém-nascido é impotente. Na sequência, surgiria a angústia da perda do objeto, na qual o perigo seria o de reviver, sem auxílio, a situação de aumento incontrolável de tensão, reproduzindo o desamparo do nascimento. A próxima desta série seria a angústia de castração, na qual o perigo seria a perda dos genitais e a possibilidade de permanecer num estado de desamparo diante da libido genital. O passo seguinte seria a angústia frente ao supereu - a angústia da consciência moral — , que assinalaria o perigo de ser castigado, de perda de amor e, no limite, de ver-se devolvido à situação de desamparo. A última modificação da angústia seria a angústia diante da morte, isto é, diante da projeção do supereu nos poderes do destino, como diz Freud. 
Laplanche (1987) comenta como Freud recapitula com isso sua teoria geral dos afetos - uma teoria que faz dos mesmos a reprodução de reações antigas, que, em seu devido tempo, tiveram a sua significação e foram, desde então, fixadas como manifestações afetivas. Assim como nos histéricos encontramos reações afetivas cujas origens repousam em acontecimentos ancestrais, os afetos típicos dos seres humanos seriam uma espécie de acesso histérico genérico, fixados ao longo do desenvolvimento filogenético e, a partir de então, congênitos.

Freud vincula as várias neuroses aos diferentes tipos de angústia. Na histeria de conversão, a principal seria a angústia frente ao perigo de perder 0 amor do objeto; nas fobias, a angústia de castração; e, na neurose obsessiva, a angústia frente ao supereu:

“Agora, vemos que não corremos perigo de declarar a angústia de castração como o único motor dos processos defensivos que levam à neurose. (...) Uma vez que sabemos com certeza que a histeria tem maior afinidade com a feminilidade, assim como a neurose obsessiva com a masculinidade, isso nos sugere a conjectura de que a perda de amor como condição de angústia desempenha na histeria um papel semelhante à ameaça de castração nas fobias, e a angústia frente ao supereu na neurose obsessiva." (FREUD, 1926/1998, p.135)

Segundo Laplanche, essas ideias têm, como consequência, uma relativização substancial do papel da castração na determinação das neuroses: “(...) quando Freud é levado a traçar em suas linhas gerais, uma espécie de correspondência entre esses perigos e as formas psicopatológicas, percebe-se que a castração deixa de ser o ponto central de tudo, uma vez que seria essencial numa única neurose, a fobia” (LAPLANCHE, 1988, p.142)

Ele parece, contudo, considerar que essas modificações introduzidas por Freud são uma espécie de retrocesso, com relação àquilo que havia sido anteriormente alcançado por ele. A seu ver, nesse momento, Freud “esquece certo número de conceitos, de instrumentos que ele tinha, por outro lado, à sua disposição e que haviam sido elaborados por ele mesmo" (ibid, p.146).

A hipótese central de Freud agora, portanto, é a de que o nascimento consistiria numa vivência traumática originária e, assim, a ocasião de uma angústia primordial que viria a atribuir caráter traumático a uma série de vivências posteriores, dando origem a uma sucessão de novas formas de angústia que estariam na base da repressão e seriam derivadas daquela gerada pelo trauma do nascimento. Com isso, Freud volta a colocar na origem das neuroses e na base do psiquismo a ação de vivências traumáticas reais. Uma vez que o nascimento é apontado como a vivência traumática originária (aquela que confere caráter traumático às demais), o nascimento e outros traumas dele derivados seriam, então, a ocasião das repressões primordiais. A angústia pela perda do amor 
da mãe, a angústia de castração e a angústia frente ao supereu forneceriam as condições de possibilidade para a repressão propriamente dita. Ou seja, os impulsos libidinais e agressivos do complexo de Édipo passariam a representar "perigos" por se associarem ao reprimido primordial e trazerem de novo a possibilidade de reviver uma situação traumática. A esses perigos, o aparelho psíquico reagiria com a repressão propriamente dita, segundo afirma a nova teoria freudiana da angústia.

\section{CONSIDERAÇÕES FINAIS}

Essas hipóteses apresentadas em Inibição, sintomas e angústia representam uma modificação significativa da teoria até então sustentada sobre a gênese das neuroses. Desde 1900, ficara estabelecido que os objetos da repressão e os fatores determinantes das neuroses seriam os desejos infantis. O que nunca chegara a ser plenamente esclarecido era por que esses desejos se tornam desprazerosos e exigem a repressão. É como se Freud tivesse tão somente substituído o modelo da vivência da dor, núcleo de sua primeira teoria do trauma, pelo da vivência de satisfação, sem estabelecer um vínculo entre eles. Com isso, os motivos da repressão tornaram-se, basicamente, externos: haveria desejos cuja realização seria inaceitável para os dispositivos normativos com os quais o indivíduo se confronta ao longo de sua educação e do processo de aquisição dos valores morais ausentes na primeira infância. Essa concepção não deixa de apresentar certo risco de subsumir o conceito metapsicológico de repressão aos termos da velha polêmica que opõe indivíduo e sociedade e, assim, identificá-lo com as formas socialmente instituídas de coerção, com evidente perda de sua originalidade inicial, como princípio interno de organização da dinâmica psíquica.

Com a vinculação do reprimido primordial aos primeiros traumas, Freud volta a situar experiências traumáticas reais na origem da repressão e das neuroses. Com isso, ele parece ter conseguido finalmente integrar os dois modelos de determinação dos fatos psíquicos (os modelos dor/trauma e satisfação/desejo, digamos assim) que, desde sua primeira formulação no Projeto, tendiam a configurar duas séries paralelas de consequências difíceis de articular entre si. Há outros ganhos teóricos que podem ser mencionados, tais como a especificação da natureza do reprimido primordial e sua relação com as exigências pulsionais, afirmada, mas não demonstrada, desde os artigos metapsicológicos.

No entanto, esses ganhos exigem o reconhecimento de toda uma série de consequências, que põe em questão aspectos decisivos dos fundamentos conceituais da psicanálise. Essas consequências incluiriam a relativização do papel da castração na etiologia das neuroses; a diminuição da importância do conflito entre as exigências sociais e a sexualidade; a ênfase maior nos fatores 
biológicos do desenvolvimento (o desamparo originário resultante da prematuração ao nascer); e assim por diante. Essas consequências parecem ter recebido pouca atenção por parte de muitos intérpretes de Freud e dos próprios psicanalistas. Um dos objetivos de reconstituir aqui o desenvolvimento do conceito freudiano de repressão foi criar uma base a partir da qual tais consequências possam ser especificadas e discutidas, já que elas têm implicações para o próprio sentido que se pode atribuir às concepções fundamentais da psicanálise freudiana, para o conhecimento psicanalítico que delas deriva e para as articulações que se podem estabelecer entre as diferentes tradições psicanalíticas e, destas, com os demais campos do saber.

Recebido em 16/2/2011. Aprovado em 11/4/2011.

\section{REFERÊNCIÄS}

CAROPRESO, F. (2008) O nascimento da metapsicologia: representação e consciência na obra inicial de Freud. São Carlos: Edufscar e Fapesp. Fapesp.

FREUD, S. (1891) Zur Auffassung der Aphasien: eine Kritische Studie. Leipzig: Franz Deuticke.

(1987) Gesammelte Werke. Frankfurt: Fischer Verlag.

. (1895) “Entwurf einer Psychologie”, Nachtragsband, p.387-477.

(1982) Studienausgabe. Frankfurt: Fischer Verlag.

(1900) “Die Traumdeutung”, v.II.

(1912) "Einige Bemerkungen über den Begriff des Unbewussten in der Psychoanalyse”, v.III, p.25-36.

(1915a) “Das Unbewusste”, v.III, p.119-162.

(1915b) “Die Verdrängung”, v.III, p.103-118.

(1920) “Jenseits des Lustprinzips”, v.III, p.213-272.

(1998). Obras completas. Buenos Aires: Amorrortu Editores.

(1892-1899) “Fragmentos de la correspondencia con Fliess", v.I, p.211322.

(1911) "Puntualizaciones psicoanalíticas sobre un caso de paranoia (Dementia paranoides) descrito autobiográficamente”, v.XII, p.1-73.

(1923) "El yo y el ello", v.XIX, p.1-66.

(1926) "Inhibición, síntoma y angustia”, v.XX, p.71-161. 
LAPLANCHE, J. (1987) Problemáticas I: A angústia. São Paulo: Martins Fontes.

(1988) Problemáticas II: Castração — Simbolizações. São Paulo: Martins Fontes.

SIMANKE, R. T \& CAROPRESO, F. (2005) O conceito de consciência no 'Projeto de uma psicologia' de Freud e suas implicações metapsicológicas. Trans/Form/Ação, v.28, n.1. 85-108, Marília: Unesp.

Fátima Caropreso

fatimacaropreso@uol.com.br

Richard Theisen Simanke

richardsimanke@uol.com.br 